\title{
Uma experiência de ensino-aprendizagem de áreas de figuras planas através da Resolução de Problemas
}

Resumo: O objetivo deste artigo foi analisar as contribuições da Metodologia de EnsinoAprendizagem-Avaliação através da Resolução de Problemas ao trabalhar em sala de aula o conteúdo de áreas de figuras. Foram participantes da pesquisa, cuja abordagem foi qualitativa, 20 alunos do Ensino Fundamental de uma escola pública da região norte do Paraná. Os resultados indicam que, mesmo diante das dificuldades, os alunos utilizaram conhecimentos prévios ao resolver o problema, mas que a estratégia tentativa e erro prevaleceu entre os grupos. Também não houve por parte dos alunos questionamentos que pudessem possibilitar a extensão do problema, o que revela que a prática de resolução de problemas em sala de aula deve ser intensificada. De todo modo, a resolução do problema analisado nesta pesquisa proporcionou aos alunos opinarem, debaterem e chegarem a um consenso, tendo o professor como mediador do processo de ensino-aprendizagem.

Palavras-chave: Educação Matemática. Figuras Planas. Resolução de Problemas.

\section{Geferson Luiz Montanholi}

Pimenta

Mestrando em Ensino de Matemática Universidade Tecnológica Federal do Paraná (UTFPR), campus Cornélio Procópio. Professor da Secretaria de Estado da Educação do Paraná (SEEPR). Paraná, Brasil.

(iD) orcid.org/0000-0003-2333-0961

$\bowtie$ gefluis@yahoo.com.br

Andresa Maria Justulin

Doutora em Educação Matemática. Professora do Programa de PósGraduação em Ensino de Matemática da Universidade Tecnológica Federal do Paraná (UTFPR), campus

Cornélio Procópio. Paraná, Brasil.

iD orcid.org/0000-0003-4107-8464

$\triangle$ andresa_justulin@yahoo.com.br

Recebido em 11/01/2021

Aceito em 14/05/2021

Publicado em 18/08/2021

\section{A teaching-learning experience of flat figure areas through Problem Solving}

Abstract: The objective of this work was to analyze the contributions of the TeachingLearning-Evaluation Methodology through Problem Solving when working in the classroom the content of areas of figures. The participants of the research, whose qualitative approach, were 20 elementary school students from a public school in the northern region of Paraná. The results indicated that, even in the face of difficulties, students used previous knowledge to solve the problem, but that the trial and error strategy prevailed between the groups. There were also no questions on the part of the students that could enable the extension of the problem, which reveals that the practice of problem solving in the classroom should be intensified. Anyway, the resolution of the problem analyzed in this research provided students with an opinion, debate and reach a consensus, having the teacher as a mediator of the teaching-learning process.

Keywords: Mathematics Education. Flat Figures. Problem Solving.

\section{Una experiencia de enseñanza-aprendizaje de áreas de figuras planas a través de la Resolución de Problemas}

Resumen: El objetivo de este trabajo fue analizar los aportes de la Metodología Enseñanza-Aprendizaje-Evaluación a través de la Resolución de Problemas al trabajar en el aula el contenido de áreas de figuras. Los participantes de la investigación, cuyo 
abordaje cualitativo, fueron 20 estudiantes de primaria de una escuela pública de la región norte de Paraná. Los resultados indicaron que, incluso ante las dificultades, los estudiantes utilizaron conocimientos previos para resolver el problema, pero que la estrategia de prueba y error prevaleció entre los grupos. Tampoco hubo preguntas por parte de los estudiantes que pudieran posibilitar la extensión del problema, lo que revela que se debe intensificar la práctica de la resolución de problemas en el aula. De todos modos, la resolución del problema analizado en esta investigación brindó a los estudiantes una opinión, un debate y un consenso, teniendo al docente como mediador del proceso de enseñanza-aprendizaje.

Palabra clave: Educación Matemática. Figuras Planas. Resolución de Problemas.

\section{Introdução}

A Matemática é uma disciplina em que o desempenho dos alunos aparece, frequentemente, abaixo do esperado tanto em avaliações internas, como a Prova Brasil, quanto externas, como o Programa Internacional de Avaliação de Estudantes (Pisa). As razões para esses resultados mostram-se variadas, desde a complexidade do conteúdo até a forma como esse conteúdo é trabalhado em sala de aula. Este último aspecto, de caráter metodológico, revela que o modo de ensinar a Matemática ainda é incipiente, o que corrobora uma aprendizagem matemática procedimental, com foco no cálculo e desconectada, muitas vezes, do fazer matemática.

Ao longo dos anos, com a evolução tecnológica, o ensino da Matemática vem passando por mudanças necessárias devido à nova característica da sociedade. Atualmente, os indivíduos têm amplo acesso a qualquer tipo de informação e no instante em que desejam. No ambiente escolar, cabe ao professor saber empregar e conduzir adequadamente suas aulas aproveitando-se das mídias para assessorar os alunos a pesquisarem e utilizarem as informações para que as atividades escolares sejam produtivas.

A Matemática pode contribuir de diversas formas para o desenvolvimento dos alunos, visto que ela apresenta um aspecto de formação intelectual relevante para o desenvolvimento de estratégias, raciocínio lógico, tomada de decisões, entre outras competências.

Segundo os Parâmetros Curriculares Nacionais de Matemática — PCN (BRASIL, 1998), a resolução de problemas é indicada como ponto de partida da atividade matemática. Essa ideia traz implícita a convicção de que o conhecimento matemático 
ganha significado quando os alunos estão diante de situações desafiadoras, que devem ser resolvidas, e trabalham em conjunto para desenvolver estratégias de resolução. Recentemente, a Base Nacional Comum Curricular - BNCC (BRASIL, 2017) retomou essas considerações ao valorizar a construção de habilidades amparadas na resolução e formulação de problemas.

A temática Grandezas e Medidas foi trazida pela BNCC (BRASIL, 2017), ao propor o estudo das medidas e das relações entre elas, ou seja, das relações métricas. Esse documento também recomenda a integração da Matemática a outras áreas de conhecimento. Para o $6^{\circ}$ ano do Ensino Fundamental, é proposta a habilidade (EF06MA24):

Resolver e elaborar problemas que envolvam as grandezas comprimento, massa, tempo, temperatura, área (triângulos e retângulos), capacidade e volume (sólidos formados por blocos retangulares), sem uso de fórmulas, inseridos, sempre que possível, em contextos oriundos de situações reais e/ou relacionadas às outras áreas do conhecimento (BRASIL, 2017, p. 303).

É importante salientar que se espera que os alunos associem a figuras geométricas grandezas como comprimento, área, volume e que resolvam problemas com essas grandezas utilizando as unidades de medida padronizadas mais usuais (BRASIL, 2017).

Em relação ao conteúdo de área de figuras planas, os PCN (BRASIL, 1998) recomenda a exploração dos procedimentos de composição e decomposição de figuras, por contagem e por estimativas e aproximações. Além disso, problemas envolvendo área e perímetro são contextos para o estudo da variação de grandezas, ou seja, os alunos podem analisar a variação da área ou do perímetro em relação ao seu lado, bem como estabelecer relações entre lados de um retângulo de mesmo perímetro ou área.

Abordando problemas sobre área de figuras planas, o escopo deste artigo é analisar as contribuições da Metodologia de Ensino-Aprendizagem-Avaliação através da Resolução de Problemas ao trabalhar esse conteúdo. As aulas destinadas ao estudo de áreas de figuras planas assumiram a ideia de o aluno resolver (ou pensar) o problema antes da apresentação formal do conteúdo, além de desenvolverem as resoluções em grupos, algo que não estavam habituados.

A fim de organização do artigo, é feita uma introdução ao tema de pesquisa, bem como é apresentado o objetivo de pesquisa. Em seguida, são trazidas as teorizações 
relativas à Resolução de Problemas. Na seção 3, os procedimentos metodológicos são descritos abarcando os participantes e os instrumentos de pesquisa utilizados. Na sequência, a seção 4 apresenta a descrição e a análise dos dados. Nas considerações finais são tecidas as principais conclusões obtidas pelos autores. Por fim, são trazidas as referências utilizadas neste trabalho.

\section{A Resolução de Problemas}

Segundo Van de Walle (2009, p. 68), um "elemento-chave para o ensino com resolução de problemas é a seleção de problemas ou tarefas apropriados”. Para o autor, um problema é definido como "qualquer tarefa ou atividade na qual os estudantes não tenham nenhum método ou regra já receitados ou memorizados e nem haja uma percepção por parte dos estudantes de que haja um método ‘correto' específico de solução" (VAN DE WALLE, 2009, p. 57).

A resolução de problemas tem como característica o envolvimento dos alunos em uma situação cuja solução não é conhecida de imediato, em que eles devem aplicar seus conhecimentos prévios na busca de uma resposta, conforme Onuchic (1999) e Van de Walle (2009). Para que isso seja possível, eles devem ter oportunidades, ser desafiados e encorajados a refletir sobre suas resoluções e a de seus colegas.

É essencial que ocorra a valorização do processo na resolução de problemas, bem como das possíveis formas de representar problemas e estratégias. De acordo com Polya (2006), é importante que os problemas sejam provocativos, pois, quando o aluno é desafiado, suas emoções e entusiasmo à procura de solução são despertadas. Dessa forma, os problemas a serem trabalhados em sala de aula não devem servir apenas como aplicação de conteúdos, em busca de resultados, definições, técnicas e demonstrações. Espera-se que os alunos sejam capazes de criar suas próprias estratégias a partir do momento em que se sintam desafiados por um problema.

Nessa direção, o professor deve estar atento a todo o processo, visto que haverá envolvimento maior de alguns e menor de outros. Sua preocupação deve ser que todos os alunos possam ter a compreensão dos conceitos envolvidos. Dentre as competências profissionais exigidas do professor em seu trabalho, segundo Van de Walle (2009), destacam-se a habilidade de planejar e de selecionar tarefas de modo que os alunos 
aprendam Matemática em um ambiente de resolução de problemas, e a habilidade de integrar a avaliação ao processo de ensino para promover a aprendizagem.

Para que a Metodologia de Ensino-Aprendizagem-Avaliação de Matemática seja colocada em prática, diversos trabalhos, como Allevato e Onuchic $(2009,2014)$ e Onuchic e Allevato (2011), trazem e ampliam o roteiro de atividades que o professor deve desenvolver em sala de aula: (1) proposição do problema, (2) leitura individual, (3) leitura em conjunto, (4) resolução do problema, (5) observar e incentivar, (6) registro das resoluções na lousa, (7) plenária, (8) busca do consenso, (9) formalização do conteúdo, e (10) proposição de novos problemas.

Vale destacar que, na metodologia proposta por Allevato e Onuchic (2014) e pelos demais trabalhos, primeiramente os alunos têm contato com o problema sem conhecer o conteúdo matemático formal necessário para a sua resolução. Assim, esse método gera debate, interação e a descoberta por parte do estudante, sem se restringir ao uso de fórmulas ou soluções sugeridas pelo professor.

Essa metodologia "reflete uma tendência de reação a caracterizações passadas como um conjunto de fatos, domínio de procedimentos algorítmicos ou um conhecimento a ser obtido por rotina ou por exercício mental" (ONUCHIC, 1999, p. 203). Ela ainda pode proporcionar aos alunos que a Matemática seja mais compreensível e tenha maior significado, uma vez que os conceitos serão investigados de maneira ativa. Cabe ressaltar que, nesse processo, o professor tem um papel fundamental, pois é dele a responsabilidade de selecionar os problemas, além de acompanhar, colaborar e incentivar os alunos durante toda a resolução, sendo um mediador do processo.

No processo "ensino-aprendizagem-avaliação", esta última é realizada durante a resolução de problemas, "integrando-se ao ensino com vistas a acompanhar o crescimento dos alunos, aumentando a aprendizagem e reorientando as práticas de sala de aula, quando necessário" (ALLEVATO e ONUCHIC, 2009, p. 139).

\section{Procedimentos Metodológicos}

A metodologia de pesquisa adotada foi a qualitativa, visto que foram considerados os dados coletados durante as aulas, por meio da discussão do problema com os alunos, de modo a identificar as devidas contribuições sobre o conteúdo trabalhado. Além disso, as atividades foram desenvolvidas em grupos, o que permitiu observar os processos e 
compreender os modos de pensar dos participantes. Outro fator foi a interação entre os alunos e o professor, sendo este também o pesquisador.

Segundo Lüdke e André (1986, p. 11), uma pesquisa qualitativa tem "o ambiente natural como sua fonte direta de dados e o pesquisador como seu principal instrumento", sempre atento ao "maior número possível de elementos presentes na situação estudada, pois um aspecto supostamente trivial pode ser essencial para a melhor compreensão do problema que está sendo estudado”.

Apoiando-se nessa abordagem, a pesquisa foi desenvolvida com uma turma do Ensino Fundamental composta por 20 alunos, durante o período de três aulas de 50 minutos cada uma. O conteúdo explorado foi o de Área de Figuras Planas, na perspectiva da Resolução de Problemas. Após uma busca na prova da Olimpíada de Matemática de 2018 em sua segunda fase, foi selecionado um problema que trabalhava a ideia de área. Ao analisá-lo, percebeu-se que o problema possibilitaria aos alunos a construção do conteúdo planejado pelo professor, sendo, portanto, um problema gerador - aquele que, deve partir dos conhecimentos prévios dos alunos e cuja resolução deve exigir um conteúdo ainda não estudado.

Primeiramente, foi entregue aos alunos o Termo de Consentimento Livre e Esclarecido para que os responsáveis assinassem. Os alunos também receberam informações sobre o Termo de Assentimento Livre e Esclarecido, o qual eles próprios deveriam assinar, caso concordassem em participar da pesquisa - conforme as resoluções CNS 466/2012 (BRASIL, 2013) e CNS 510/2016 (BRASIL, 2016). Na aula seguinte, os Termos foram recolhidos, com ciência e concordância dos responsáveis e de todos os alunos da turma.

Dando início à coleta de dados, entregou-se o problema impresso aos alunos, que, após leitura individual, dividiram-se em pequenos grupos para que pudessem iniciar a atividade. De fato, os alunos se interessaram e participaram das atividades propostas. Foram coletados os dados, os registros escritos da resolução do problema, e, depois, os grupos colocaram as resoluções na lousa. No decorrer das aulas questionamentos foram levantados por ambas as partes, professor e alunos, enriquecendo, desse modo, o processo ensino-aprendizagem. 
As resoluções e questionamentos dos alunos foram baseados na observação sobre os modos como eles resolveram o problema apresentado pelo professor em material impresso. No decorrer do processo, cada grupo indicou um representante para explicar na lousa a maneira como resolveu o problema. Esse momento foi enriquecedor, já que cada equipe pôde expor o método utilizado para a solução, mostrando aos demais colegas da sala de aula outras formas de resolver a atividade, compartilhando os mais diversos conhecimentos, concluindo que não há um único caminho correto.

No transcorrer da atividade, o professor pediu aos alunos que fizessem suas considerações, aguçando, assim, o senso crítico, visando que cada grupo buscasse caminhos diversos para chegar ao resultado. Foi possível registrar esse momento por meio de anotações e fotos dos processos utilizados.

Após concluírem a resolução do problema e exporem seus resultados na lousa, o professor fez a devida formalização, organizando e estruturando em linguagem matemática. Na sequência, foram propostos novos problemas para que os alunos aplicassem os conceitos abordados.

Para a análise dos dados, foram levados em consideração as falas dos alunos, o registro do professor e as fotos das produções dos alunos. Por meio desse material, foi possível observar os anseios, a forma de pensar, a troca de informações e as conquistas obtidas pelos participantes com a resolução do problema.

\section{Descrição e análise dos dados}

As atividades foram desenvolvidas em três encontros e estavam presentes, nessa turma de $6^{\circ}$ ano, 20 alunos. É conveniente destacar que se trata de uma classe com um número reduzido de alunos, o que se acredita ter contribuído para o sucesso do trabalho desenvolvido.

No início da primeira aula, foi solicitado que os alunos se organizassem em cinco grupos. Como havia 20 estudantes, cada grupo foi composto por 4 alunos. A identificação dos envolvidos no processo ocorrerá da seguinte forma: professor, grupo 1, grupo 2, grupo 3, grupo 4, grupo 5, aluno do grupo 1, aluno do grupo 2 e assim por diante. Antes de entregar o problema aos alunos para que iniciassem a resolução, o professor teve que expor algumas regras: não se comunicar com os outros grupos; fazer uma leitura individual do problema, seguida de uma leitura em grupo e cada grupo deveria escolher 
um integrante para ir à lousa expor as resoluções e explicá-las, a fim de que os resultados fossem comparados. Após essas informações, foi entregue uma folha a cada estudante contendo o problema, conforme mostra a Figura 1.

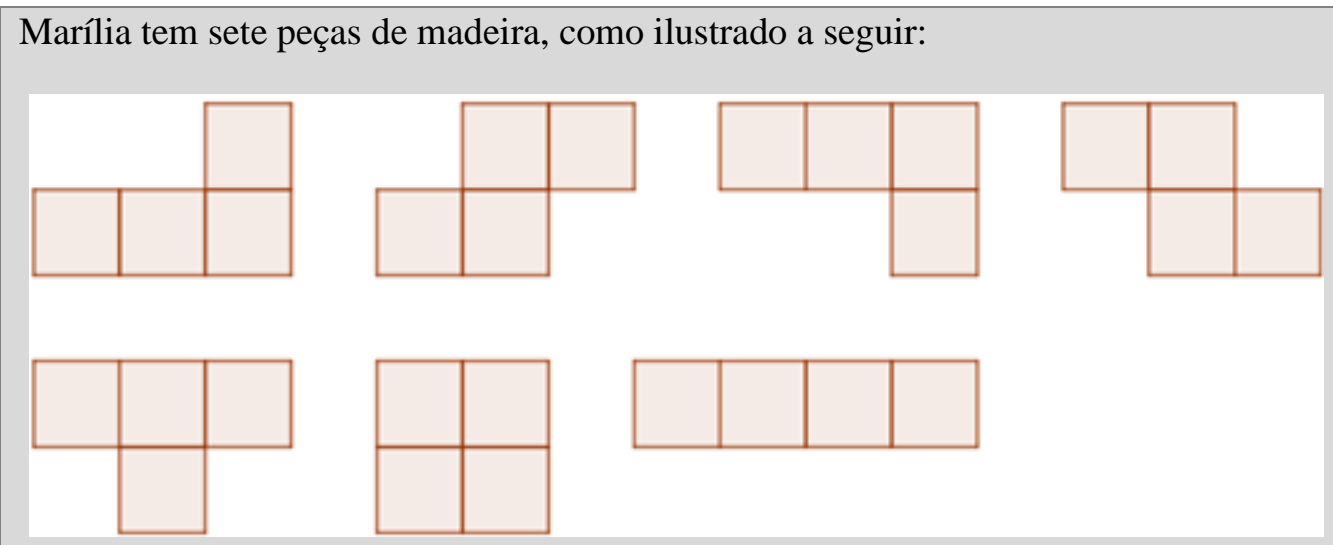

Ela brinca de cobrir todas as casas de tabuleiros retangulares com essas peças, sem colocar uma peça sobre outra. Cada peça deve cobrir exatamente 4 casas do tabuleiro.

a) Cubra o tabuleiro abaixo usando três peças de Marília.

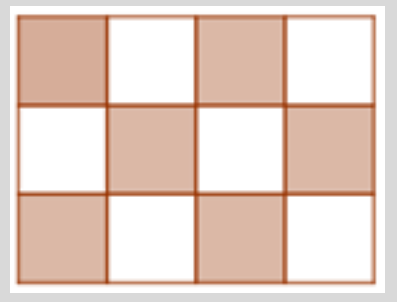

b) Qual peça não cobre o mesmo número de casas brancas e casas marrons de um tabuleiro?

c) Explique por que Marília nunca irá conseguir cobrir o tabuleiro abaixo.

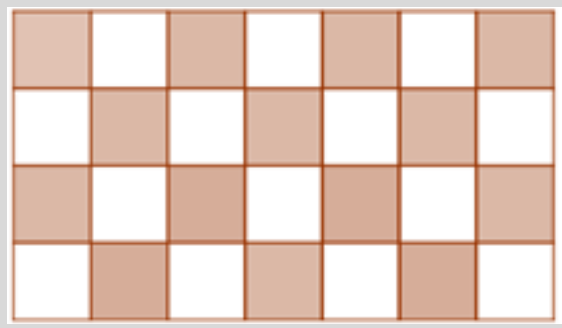

Figura 1: Problema apresentado aos alunos (Adaptado de Olimpíada Brasileira de Matemática)

Depois de entregue o problema, os alunos começaram a fazer a leitura e as devidas resoluções. Vale a pena ressaltar que, por se tratar de uma atividade desenvolvida na perspectiva do Ensino-Aprendizagem-Avaliação de Matemática através da Resolução de Problemas, conforme recomendado por Onuchic e Allevato (2011) e Allevato e Onuchic 
(2014), não houve qualquer informação quanto ao conteúdo. O professor, no momento de seleção do problema, levou em conta os conhecimentos prévios dos alunos, ou seja, nos Anos Iniciais do Ensino Fundamental eles já haviam trabalhado com áreas de figuras planas, de modo conceitual ou declarativo. O objetivo do professor era o de desenvolver o aspecto procedimental. Assim, esse foi um problema inicial ou de retomada, para alguns, vislumbrando o desenvolvimento do conteúdo de áreas de figuras planas no $6^{\circ}$ ano do Ensino Fundamental.

Após receberem a folha contendo o problema juntamente com moldes recortados, os alunos indagaram o professor quanto às peças que lhes foram entregues, sendo informados de que elas faziam parte do problema. Outro ponto que merece atenção, é o fato que os alunos tiveram que fazer uma leitura individual e em grupo para darem início à resolução do problema. Segundo Allevato e Onuchic (2014), essa é uma etapa no qual o aluno "tem possibilidade de refletir, de colocar-se em contato com a linguagem matemática e desenvolver sua própria compreensão do problema proposto" (p. 45). Na sequência, começaram a resolver o item a).

Percebeu-se que três grupos iniciaram a resolução colocando as peças sobre o tabuleiro, utilizando-se de tentativas, enquanto os demais estavam discutindo como iniciar a resolução.

Grupo 1: Professor, são 12 quadrados dentro do retângulo e como cada peça contém 4 quadrados, utilizando 3 blocos vou conseguir completar, certo?

Professor: Por que vocês acreditam que isso dará certo?

Grupo 1: (Após pensar um tempo) Nós contamos e percebemos que o tabuleiro contém 12 quadrados e 3 peças separadas, também possuem um total de 12 quadrados, assim dará certo.

Professor: Façam as devidas tentativas e verifiquem se o tabuleiro será completado.

Na Figura 2 consta a solução apresentada pelo grupo 1. 
a) Cubra o tabuleiro abaixo usando três peças de Marília.
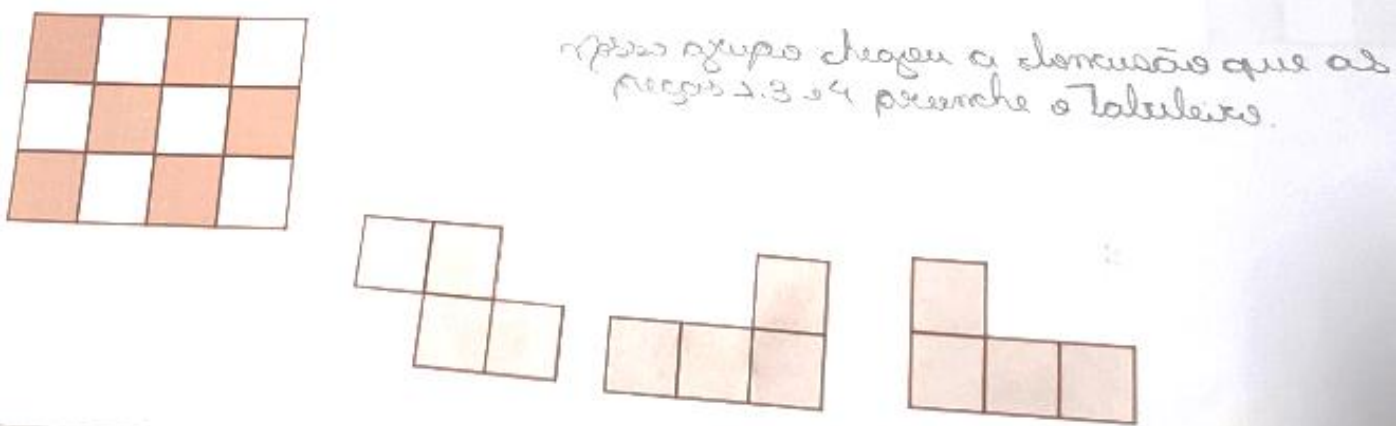

Figura 2: Resposta apresentado pelo grupo 1 (Dados da Pesquisa)

Os demais grupos deram prosseguimento à atividade até o momento em que outro grupo disse ter resolvido o item.

Grupo 2: Professor, montamos as peças encaixando e conseguimos formar o tabuleiro.

Professor: Como vocês conseguem perceber que está correto?

Grupo 2: Ah, Professor! Formou dois retângulos iguais.

O professor solicitou que os alunos registrassem o que haviam pensado. Depois eles mostraram a solução conforme Figura 3.

a) Cubra o tabuleiro abaixo usando três peças de Marília.
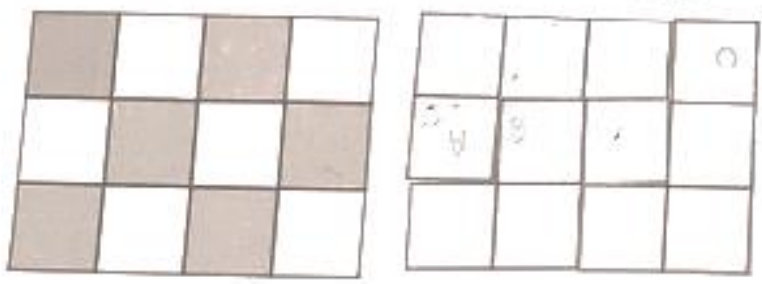

Figura 3: Resposta apresentado pelo grupo 2 (Dados da Pesquisa)

Nos demais grupos, observou-se que também estavam utilizando as peças para tentar completar o tabuleiro. Após um tempo, o grupo 3 disse ao professor que tinha chegado à resposta.

Grupo 3: Professor, conseguimos resolver!

Professor: Como?

Grupo 3: Percebemos que juntando três peças dá certo.

Professor: Mostrem!

Grupo 3: Usando as peças A, Ce F. 
Esse grupo classificou as peças da letra A até a letra G. Segue a resolução exposta pelo grupo 3 (Figura 4).

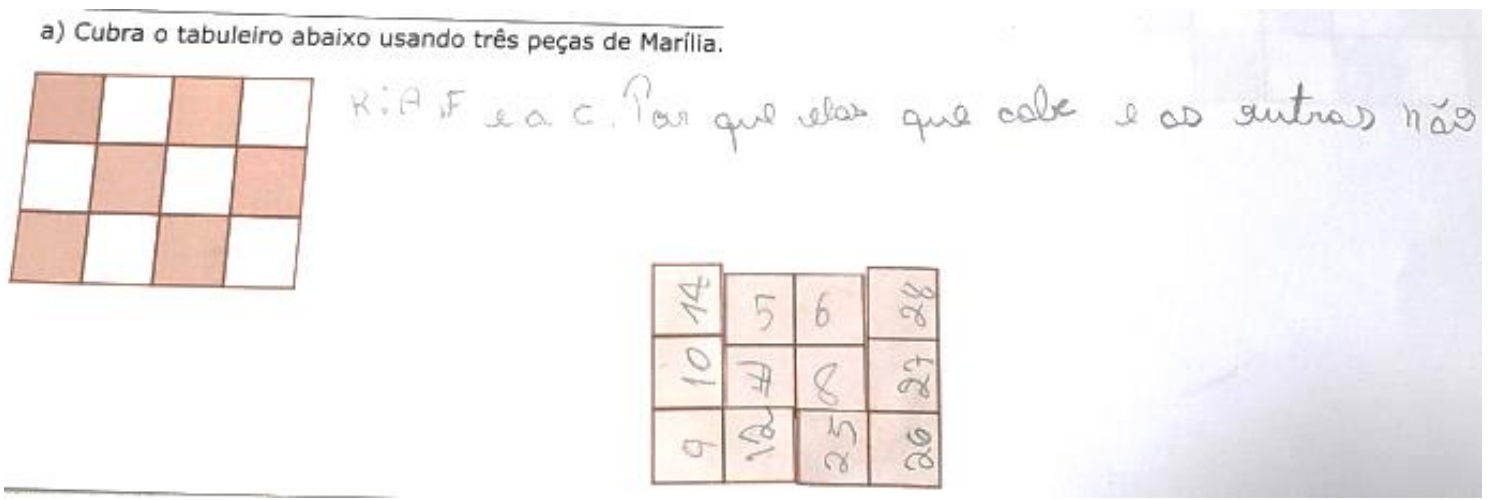

Figura 4: Resposta apresentada pelo grupo 3 (Dados da Pesquisa)

Os demais grupos conseguiram distribuir as peças dentro do tabuleiro, sendo empregadas as peças recortadas para auxiliá-los a pensar como resolver. Pode-se perceber que, em nenhuma parte do problema, os alunos questionaram se haveria mais de uma forma de resolver o problema ou, ainda, quantas soluções seriam possíveis. De acordo com Correa e Noguti (2020, p. 24), essa "mudança de postura perante o aluno requer prática, uma vez que os professores, em específico de Matemática, estão bem habituados em responder os questionamentos dos alunos".

Além disso, percebeu-se que as peças entregues aos alunos tiveram um papel fundamental nas tentativas de encontrarem a solução à primeira pergunta. Ademais, de acordo com Allevato e Onuchic (2014, p. 45), "para resolver o problema, os alunos precisam de linguagem matemática ou de outros recursos de que dispõem: linguagem corrente, desenhos, gráficos, tabelas ou esquemas".

No item b), que continha a pergunta: Qual peça não cobre o mesmo número de casas brancas e casas marrons de um tabuleiro? em um dos grupos, surgiu dúvida com relação ao que estava sendo solicitado:

\section{Grupo 2: O que devo fazer neste item?}

Professor: Leiam novamente a pergunta e verifiquem o que a mesma quer dizer.

O grupo 2 leu novamente o enunciado, e seus integrantes iniciaram a resolução. Enquanto isso, os outros grupos resolviam esse item utilizando-se das peças e fazendo tentativas até descobrirem a peça que não cobria o mesmo número de casas brancas e 
marrons.

Grupo 3: Encontramos a peça correta.

Professor: Como?

Grupo 3: Fomos testando as peças e percebemos que a no formato de letra $T$ não cobre o mesmo número de casas.

Professor: E as outras peças?

Grupo 3: Já verificamos professor e todas as outras cobrem duas brancas e duas marrons.

Professor: Registrem o que fizerem e confiram se realmente esta peça é a correta.

A Figura 5 apresenta a resposta dada pelo grupo 3.

b) Qual peça não cobre o mesmo número de casas brancas e casas marrons de um tabuleiro?
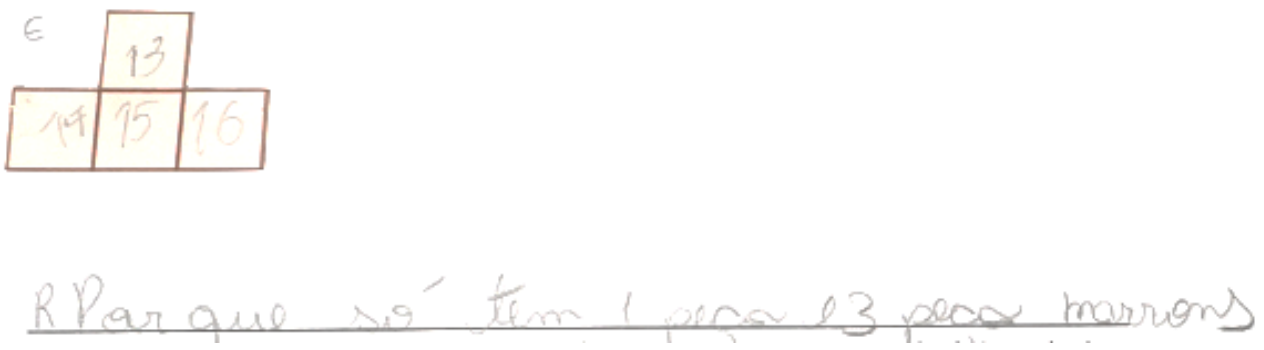

Figura 5: Solução apresentado pelo grupo 3 (Dados da Pesquisa)

Em seguida, o grupo 4 disse ter conseguido chegar à resposta.

Grupo 4: Professor, descobrimos a peça que não cobre o mesmo número de casas.

Professor: De que forma?

Grupo 4: Colocamos as peças sobre o tabuleiro e descobrimos que é no formato de $T$.

Professor: Registrem o que fizeram.

Na Figura 6, consta a solução apresentada pelo grupo 4.

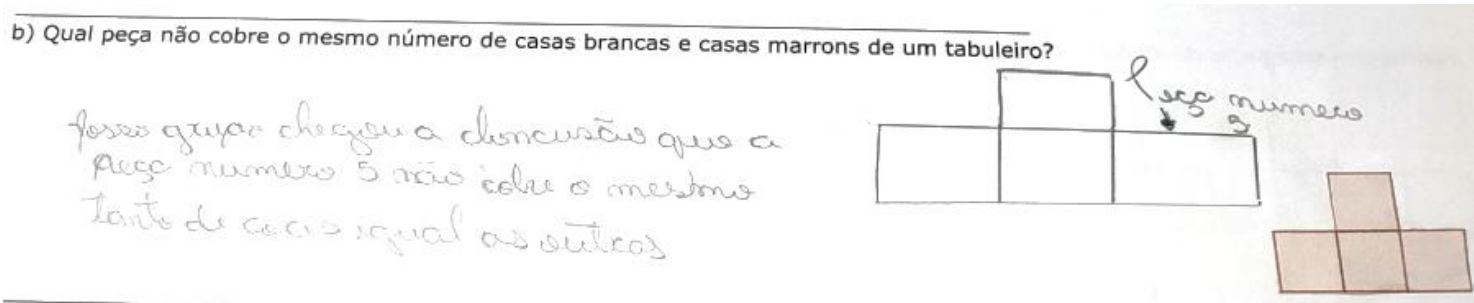

Figura 6: Solução apresentado pelo grupo 4 (Dados da Pesquisa) 
* Escrita do aluno: Nosso grupo chegou a conclusão que a peça número 3 não cobre o mesmo tanto de casas igual as outras

Os outros grupos também foram concluindo o item e conseguiram, de maneira similar, encontrar a peça. Nota-se que a tentativa e erro, definida em Dante (2009), foi a principal estratégia utilizada pelos alunos.

No item c) os alunos tiveram uma maior dificuldade. Eles tentaram colocar todas as peças no retângulo, porém não se encaixavam.

Grupo 5: Professor temos 28 quadradinhos dentro do retângulo e as peças também tem 28 quadradinhos, porque não completa então.

O professor instigou que os alunos observassem a pergunta anterior e a partir desta análise tivessem condições de iniciar a resolução.

A partir deste momento os grupos tentaram cobrir o tabuleiro sem êxito, pois até então, não conseguiram perceber um caminho para a solução. Após um tempo e vários testes o grupo 2 chegou à solução.

Grupo 2: Professor, o que faz com que o tabuleiro não complete é a peça em formato de $T$, pois ela não cobre o mesmo número de casas brancas $e$ marrons, assim irá sobrar casas sem preencher.

Professor: Vocês têm certeza disso?

Grupo 2: Sim professor porque todas cobrem as cores iguais e essa não.

Professor: Confiram se a resolução está correta e façam as devidas anotações.

Na sequência, observa-se a resposta dada pelo grupo 2 .

c) Explique por que Marília nunca irá conseguir cobrir o tábuleiro abaixo.
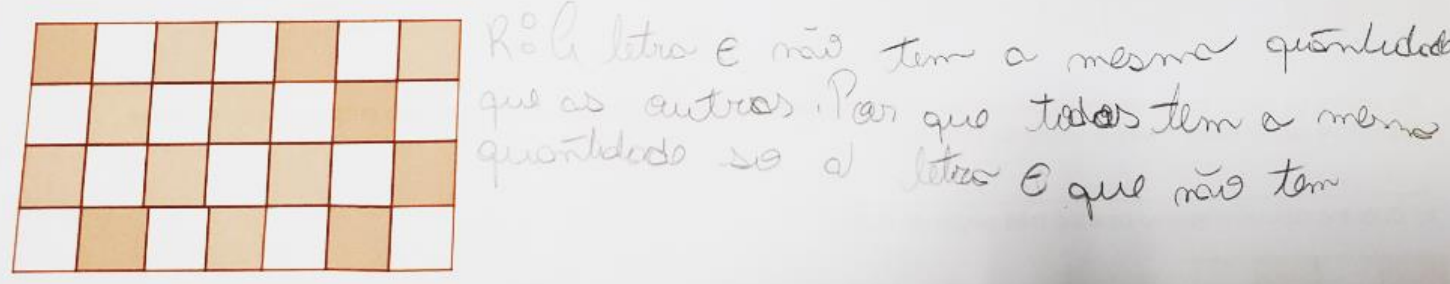

Figura 7: Solução apresentado pelo grupo 2 (Dados da Pesquisa)

* Escrita do aluno: A letra E não tem a mesma quantidade que as outras. Por que todas tem a mesma quantidade só a letra E que não tem.

Logo depois, o grupo 1 também disse ter resolvido.

Grupo 1: Também conseguimos. 
Professor: Como vocês pensaram?

Grupo 1: Professor, todas as peças cobrem duas casas marrons e duas casas brancas e a peça em formato de T cobrem três casas brancas e uma marrom, por isso ficarão casas sem cobrir, assim o tabuleiro não ficará todo preenchido.

Professor: Todos do grupo concordam com esta solução?

Grupo 1: Sim professor pois fizemos várias tentativas e essa não deixa cobrir casas de mesma quantidade.

Professor: Façam as anotações na folha que lhes foi entregue.

A resolução apresentada pelo grupo 1 consta na Figura 8.

c) Explique por que Marília nunca irá conseguir cobrir o tabuleiro abaixo.
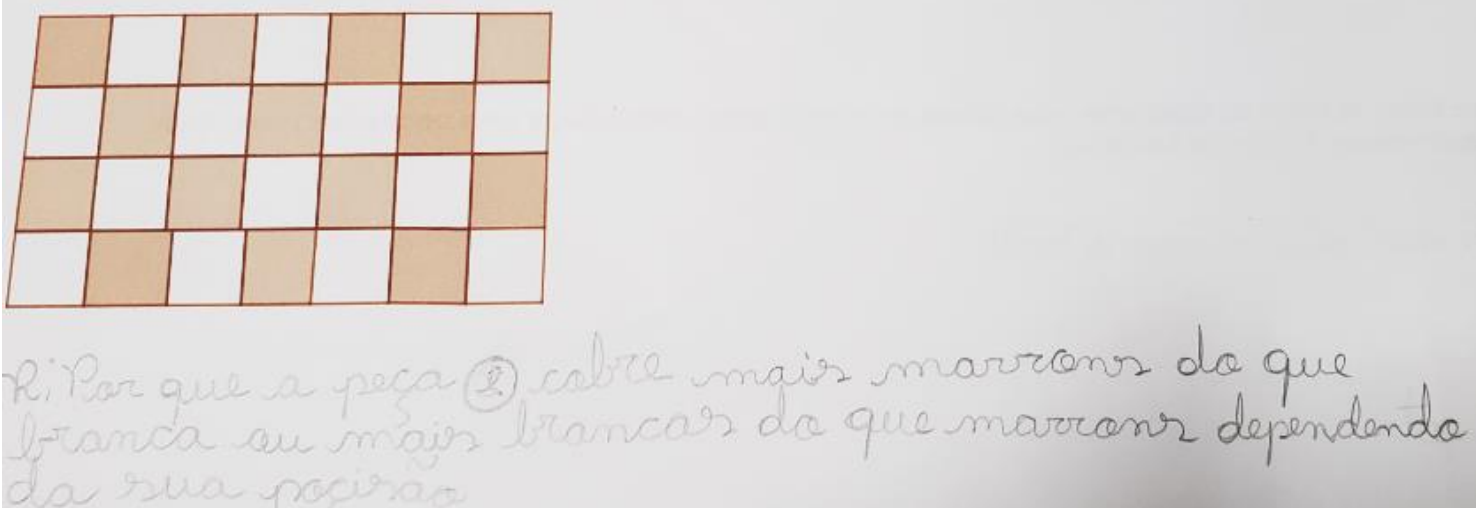

Figura 8: Solução apresentado pelo grupo 1 (Dados da Pesquisa)

*Escrita do aluno: Porque a peça "e" cobre mais marrons do que branca ou mais brancas que marrons dependendo da sua posição.

Os demais grupos também foram chegando à conclusão de que a peça no formato de letra T fazia com que o tabuleiro não fosse totalmente completado. Em seguida, um integrante de cada grupo foi até a lousa expor os resultados e explicar como haviam resolvido cada item do problema. A Figura 9 mostra as respectivas soluções.

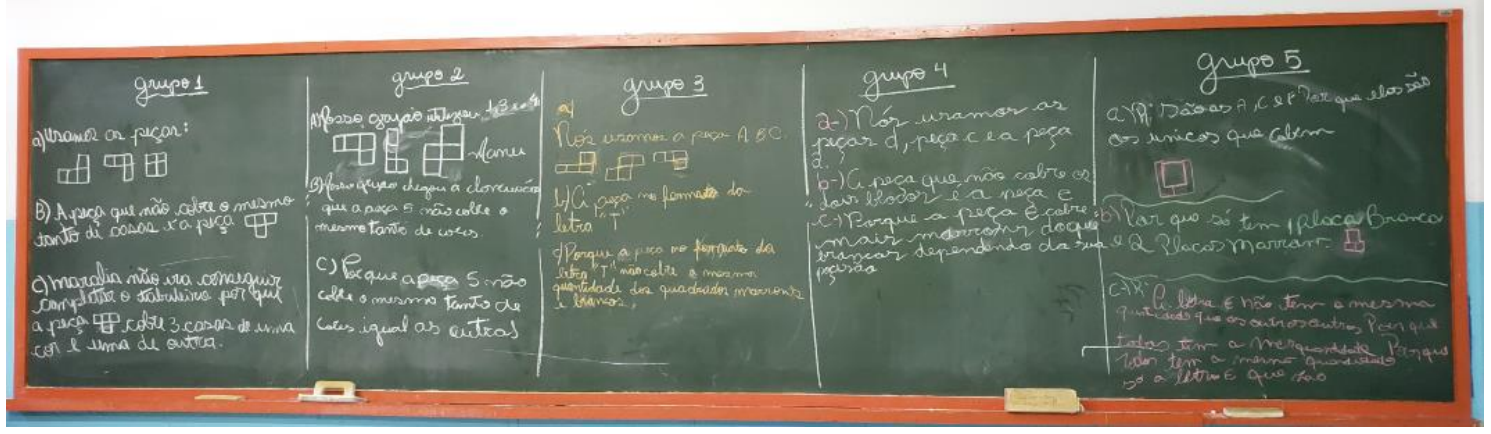

Figura 9: Solução do problema apresentado pelos grupos (Dados da Pesquisa)

Durante a realização da atividade, os alunos poderiam ter utilizado ideias sobre 
multiplicação, potenciação, entre outras, que lhes permitiriam resolver o problema através de procedimentos distintos. No entanto, não se apoiaram em procedimentos ou cálculos matemáticos, mas, sim, no contexto do tabuleiro, o que revela a habilidade EF06MA24 da BNCC (BRASIL, 2017).

Após os alunos exporem seus resultados na lousa, o professor fez a devida formalização, apresentando que o conteúdo desenvolvido na atividade tratava de área de figuras planas. Foram revisados com os alunos os conceitos de área do quadrado e do retângulo e, em seguida, propuseram-se novos problemas. Esta etapa de propor novos problemas, possibilitou verificar se houve a compreensão do conteúdo Área de Figuras Planas.

No desenvolvimento das atividades em grupo os alunos discutiram ideias, bem como desenvolveram suas estratégias para obterem suas conclusões. Para Masola e Allevato (2018, p. 54), “em particular, no caso da Matemática, os alunos devem aprender os conteúdos dessa disciplina com compreensão, produzir ativamente novos conhecimentos a partir de seus conhecimentos prévios". A pesquisa revelou que os grupos auxiliaram neste processo.

\section{Considerações Finais}

As atividades propostas aos alunos e descritas neste trabalho foram desenvolvidas segundo a perspectiva de Resolução de Problemas. Com essa abordagem de ensino, a construção de conceitos levou em consideração o conhecimento prévio dos alunos, suas hipóteses, suas sugestões.

De um modo geral, os alunos mostraram-se interessados e apresentaram uma participação ativa durante o decorrer das aulas. Essa participação é importante para que eles troquem ideias, possam tomar decisões, elaborar estratégias, compartilhar experiências, comunicarem-se e interagir, construindo, assim, conhecimento.

A partir das atividades desenvolvidas e relatadas, constatou-se que os alunos apresentaram capacidade de análise, interpretação e resolução sobre área do quadrado e do retângulo. Outros tipos de área foram mencionados durante as aulas, porém não houve aprofundamento devido ao tempo de que se dispunha, também porque o foco principal era explorar área do quadrado e do retângulo. 
Considerando os comentários dos alunos sobre o problema trabalhado, ficou evidente que esse tipo de problema está presente em seu dia a dia. Portanto, o fato de estudá-lo se torna relevante, pois o estudante constituirá conhecimento para aplicar em suas decisões.

Para ser autônomo, os alunos precisam, entre outras coisas, que o professor lhes dê espaço para se expressarem, pois eles não são seres sem conhecimento sobre o assunto em questão. Ao contrário, eles possuem conhecimentos que podem ser explorados, podendo apresentá-los, discuti-los, estruturá-los.

Com este artigo foi possível evidenciar que o professor pode propiciar situações de aprendizagem das quais os alunos participem de forma ativa, sentindo-se capazes da construção do seu próprio conhecimento. Isso proporciona uma aprendizagem mais efetiva.

De acordo com os autores estudados, bem como com a experiência adquirida em sala de aula enquanto professor e por meio de conversas com professores da mesma área, verifica-se que muitos alunos não percebem a ligação entre a Matemática ensinada na escola e a praticada no cotidiano. Uma das causas disso pode ser o fato de que, ainda hoje, muitos professores têm dificuldade em construir os conteúdos, trabalhando na maioria das vezes apenas com exercício algorítmico, visando à memorização. A utilização da Resolução de Problemas, enquanto estratégia de ensino, pode contribuir para reverter essa situação.

\section{Referências}

ALLEVATO, Norma Suely Gomes; ONUCHIC, Lourdes de la Rosa. Ensinando Matemática na sala de aula através da Resolução de Problemas. Boletim GEPEM, Rio de Janeiro, n. 55, p. 133-154, 2009.

ALLEVATO, Norma Suely Gomes; ONUCHIC, Lourdes de la Rosa. EnsinoAprendizagem-Avaliação de Matemática: porque através da Resolução de Problemas? In: ONUCHIC, Lourdes de la Rosa; ALLEVATO, Norma Suely Gomes; NOGUTI, Fabiane Cristina Hopner; JUSTULIN, Andresa Maria. (Org.). Resolução de Problemas: teoria e prática. Jundiaí: Paco Editorial, 2014, p. 35-52.

BRASIL. Ministério da Educação. Secretaria de Educação Básica. Base Nacional Comum Curricular. Brasília, 2017. 
BRASIL. Ministério da Educação. Secretaria de Educação Fundamental. Parâmetros Curriculares Nacionais: Matemática. Brasília: MEC/SEF, 1998.

BRASIL. Ministério da Saúde. Conselho Nacional de Saúde. Resolução n. 466, de 12 de dezembro de 2012. Trata sobre as diretrizes e normas regulamentadoras de pesquisa envolvendo seres humanos. Brasília: Diário Oficial da União, 13 jun. 2013.

BRASIL. Ministério da Saúde. Conselho Nacional de Saúde. Resolução n. 510, de 7 de abril de 2016. Trata sobre as diretrizes e normas regulamentadoras de pesquisa em ciências humanas e sociais. Brasília Diário Oficial da União, 24 maio. 2016.

CORREA, Matheus Metz; NOGUTI, Fabiane Cristina Höpner. O Ensino-AprendizagemAvaliação de Progressão Geométrica através da Resolução de Problemas na Licenciatura em Matemática. Educação Matemática Debate, Montes Claros, v. 4, n. 10, p. 1-26, 2020.

DANTE, Luiz Roberto. Formulação e resolução de problemas de matemática: teoria e prática. São Paulo: Ática, 2009.

LÜDKE, Menga; ANDRÉ, Marli Eliza Dalmazo Afonso. Pesquisa em Educação: abordagens qualitativas. São Paulo: EPU, 1986.

MASOLA, Wilson de Jesus; ALlEVATO, Norma Suely Gomes. Dificuldades de aprendizagem matemática: algumas reflexões. Educação Matemática Debate, Montes Claros, v. 3, n. 7, p. 52-67, jan./abr. 2019.

ONUCHIC, Lourdes de la Rosa. Ensino-aprendizagem de Matemática através da resolução de Problemas. In: BICUDO, Maria Aparecida Viggiani. (Org.). Pesquisa em Educação Matemática. São Paulo: Ed UNESP, 1999, p. 199-218.

ONUCHIC, Lourdes de la Rosa; ALlEVATO, Norma Suely Gomes. Pesquisa em Resolução de Problemas: caminhos, avanços e novas perspectivas. Bolema, Rio Claro, v. 25, n. 41, p. 73-98, dez. 2011.

POLYA, George. A arte de resolver problemas: um novo aspecto do método matemático. 2. ed. Tradução de Heitor Lisboa de Araujo. Rio de Janeiro: Interciência, 2006.

VAN DE WALLE, John. Matemática no Ensino Fundamental: formação de professores e aplicação em sala de aula. Tradução de Paulo Henrique Colonese. 6. ed. Porto Alegre, 2009. 